\title{
Nondestructive Structural Investigation of Yttria-Stabilized Zirconia Fiber Insulation Tile by Synchrotron X-ray In-Line Phase-Contrast Microtomography
}

\author{
Shengkun Yao ${ }^{1,2, *(\mathbb{D}}$, Benxue Liu ${ }^{3}$, Jing Ren ${ }^{1,2}$, Jingwen Liu ${ }^{1,2}$, Meili $\mathrm{Qi}^{4}$ and Yangjian Cai ${ }^{1,2}$ \\ 1 Shandong Provincial Engineering and Technical Center of Light Manipulations \& Shandong Provincial Key \\ Laboratory of Optics and Photonic Device, School of Physics and Electronics, Shandong Normal University, \\ Jinan 250358, China; rjing0914@163.com (J.R.); ljw13181392312@163.com (J.L.); yangjiancai@sdnu.edu.cn (Y.C.) \\ 2 Collaborative Innovation Center of Light Manipulations and Applications, Shandong Normal University, \\ Jinan 250358, China \\ 3 Shandong Key Laboratory for Special Silicon-Containing Material, Advanced Materials Institute, Qilu \\ University of Technology (Shandong Academy of Sciences), Jinan 250014, China; liubenxue@sdas.org \\ 4 School of Traffic and Civil Engineering, Shandong Jiaotong University, Jinan 250357, China; \\ qimeili@sdjtu.edu.cn \\ * Correspondence: yaoshk@sdnu.edu.cn
}

Citation: Yao, S.; Liu, B.; Ren, J.; Liu, J.; Qi, M.; Cai, Y. Nondestructive Structural Investigation of Yttria-Stabilized Zirconia Fiber Insulation Tile by Synchrotron X-ray In-Line Phase-Contrast Microtomography. Photonics 2021, 8, 338. https:// doi.org/10.3390/photonics8080338

Received: 9 July 2021

Accepted: 13 August 2021

Published: 17 August 2021

Publisher's Note: MDPI stays neutral with regard to jurisdictional claims in published maps and institutional affiliations.

Copyright: (c) 2021 by the authors. Licensee MDPI, Basel, Switzerland. This article is an open access article distributed under the terms and conditions of the Creative Commons Attribution (CC BY) license (https:// creativecommons.org/licenses/by/ $4.0 /)$.

\begin{abstract}
Zirconia $\left(\mathrm{ZrO}_{2}\right)$ aerogels show excellent insulating performance and have been widely applied as a thermal protector in furnaces, nuclear reactors, and spacecraft. The nondestructive determination of their interior microstructure is significant for evaluating their mechanical and insulating performance. In this study, we performed nondestructive structural investigation of an yttria-stabilized $\mathrm{ZrO}_{2}$ fiber insulation tile using synchrotron $\mathrm{X}$-ray in-line phase-contrast microtomography at a pixel resolution of $6.5 \mu \mathrm{m}$. Taking advantage of the edge enhancement of phase-contrast imaging, single yttria-stabilized $\mathrm{ZrO}_{2}$ fibers were clearly distinguished; furthermore, interior aggregates were nondestructively observed at this spatial resolution. This work demonstrates the advantages and potential of synchrotron X-ray microtomography for the structural analysis of porous ceramic materials. By combining higher-brilliance synchrotron radiation sources and CCD detectors with higher spatial and temporal resolutions, we anticipate that we can further understand the relationship between aerogel microstructure and function, especially under in-service conditions at high temperatures.
\end{abstract}

Keywords: synchrotron radiation; $\mathrm{X}$-ray microscopy; $\mathrm{X}$-ray tomography; phase contrast; yttria-stabilized $\mathrm{ZrO}_{2}$ fiber; thermal insulation materials

\section{Introduction}

Thermal insulation materials are widely used in aerospace, chemical production, housing construction, the food industry, energy transmission, and other fields [1,2]. In space exploration, aerogels, porous materials that are excellent thermal insulators, play irreplaceable roles, mainly being used in the insulation of aircraft and spacesuits [3,4]. Porous aerogels demonstrate obvious advantages compared to traditional thermal insulation materials, realizing an equivalent thermal insulation effect but with a smaller volume and lighter weight [5]. In house construction, thermal insulation materials are generally polymer-based materials, such as polystyrene and polyurethane foam, which effectively inhibit the radiation heat of the sun or infrared rays, inhibit the heat radiation and heat loss of high-temperature objects, maintain $70 \%$ of indoor heat, effectively maintain lowtemperature objects cold, and inhibit the cooling loss caused by radiant heat loss to the environment [6-8]. To satisfy their use in a complex work environment, various kinds of aerogels have been developed, such as metal oxide aerogels $\left(\mathrm{Al}_{2} \mathrm{O}_{3}, \mathrm{ZrO}_{2}\right)$, nitride 
aerogels $\left(\mathrm{Si}_{3} \mathrm{~N}_{4}, \mathrm{BN}\right)$, carbon aerogels, boride aerogels $\left(\mathrm{ZrB}_{2}, \mathrm{HfB}_{2}\right)$, and carbide aerogels $(\mathrm{SiC}, \mathrm{ZrC})[9,10]$.

Among all aerogels, fibrous zirconia ceramics with ultrahigh porosity $\left(\mathrm{a} \mathrm{ZrO}_{2}\right.$ aerogel), a kind of three-dimensional nanoporous material with randomly assembled $\mathrm{ZrO}_{2}$ nanoparticles or fibers, show tremendous application potential owing to their special properties, such as a high melting point $\left(\sim 2715^{\circ} \mathrm{C}\right)$, low thermal conductivity, and excellent mechanical strength [11,12]. Theoretically, to achieve the lowest thermal conductivity, $\mathrm{ZrO}_{2}$ aerogels are the best inorganic aerogel candidate $[13,14]$. This material has been widely applied. The excellent heat insulation performance of $\mathrm{ZrO}_{2}$ aerogels is attributed to its unique porous ultrastructure $[9,15]$. However, the fractal structures, the most prominent characterization of $\mathrm{ZrO}_{2}$ aerogels, are gradually lost when annealing at high temperatures $\left(\sim 600^{\circ} \mathrm{C}\right)$. The specific area decreases drastically from $406 \mathrm{~m}^{2} / \mathrm{g}$ to $26 \mathrm{~m}^{2} / \mathrm{g}$ when calcined at $1000{ }^{\circ} \mathrm{C}$. Consequently, the thermal insulation effect decreases drastically [16-18]. Therefore, further understanding the structure-property relationships is of vital importance to improve the thermal stabilities of $\mathrm{ZrO}_{2}$ aerogels at high temperature.

For the structural characterization of ceramic materials, optical microscopy, atomic force microscopy, and electron microscopy are commonly applied [19]. However, only two-dimensional information of the material surfaces is obtained in the process. To realize three-dimensional analysis, the materials have to be sectioned and subsequently observed under a microscope. This process is time-consuming, and a more serious drawback is that the sample is destroyed during the sectioning process. To keep the original microstructure and nondestructively perform structural analysis in three dimensions, X-ray tomography is a good choice [20-23]. X-ray tomography can realize structural analysis at a multiscale resolution from millimeters to microns without destroying the tested samples, owing to the strong penetration power and short wavelength of X-rays [24-26]. X-ray tomography has been used for the structural and damage characterization of ceramic materials to investigate their changes in pore morphology and interconnectivity [27-30]. Moreover, dynamic microstructural evaluations during sintering or compaction processes have also been performed $[25,26,31,32]$. However, the spatial resolution and contrast resolution are limited in laboratory-based X-ray microscopy $[33,34]$.

With the development of synchrotron radiation light sources worldwide, $\mathrm{X}$-ray microscopy has shown broader applications in material science, biology, and industrial areas [33,35-38]. Recently, to improve image contrast, various phase-contrast imaging techniques have been developed, including propagation-based imaging (i.e., in-line phasecontrast imaging), X-ray interferometry, grating-based imaging, and analyzer-based imaging [39-42]. Among the phase-contrast imaging methods, in-line phase-contrast X-ray imaging is suitable for various applications due to its simplicity [43,44]. A beam with sufficient spatial coherence and an appropriate sample-to-detector distance can attain phase-contrast information without any additional optical components. The acquired projections can be reconstructed with and without phase retrieval at a single distance to emphasize characteristic structures.

In this study, we performed nondestructive structural investigation of an yttriastabilized $\mathrm{ZrO}_{2}$ fiber insulation tile using synchrotron $\mathrm{X}$-ray in-line phase contrast microtomography. Single yttria-stabilized $\mathrm{ZrO}_{2}$ fibers were distinguished clearly, and the interior aggregates were nondestructively observed by taking advantage of the edge enhancement of phase-contrast imaging. This work demonstrates the advantages and potential of synchrotron X-ray microtomography in the structural analysis of porous ceramic materials. By combining higher-brilliance synchrotron radiation sources and CCD detectors with higher spatial and temporal resolutions, $\mathrm{X}$-ray tomography will be a powerful technique to further understand the relationship between aerogel microstructure and function. 


\section{Materials and Methods}

\subsection{Sample Preparation}

The yttria-stabilized $\mathrm{ZrO}_{2}$ insulation tile was fabricated by mixing a slurry of zirconia fibers (8 mol. \% $\mathrm{Y}_{2} \mathrm{O}_{3}-\mathrm{ZrO}_{2}$, Anhui Crystal New Materials Co. Ltd., China) and silica binder, followed by vacuum molding and sintering. Typically, yttria-stabilized $\mathrm{ZrO}_{2}$ fibers with a diameter of 4-7 $\mu \mathrm{m}$ were chopped using a blender to produce a slurry in which a $5 \mathrm{wt} . \%$ silica binder (HA2005, Peak-Tech New Material Co. Ltd., China) was added. Then, the slurry was vacuum-molded to remove excess water and to form a soft felt. After drying in an oven at $120^{\circ} \mathrm{C}$ for $24 \mathrm{~h}$, the dried felt was heated to $1500^{\circ} \mathrm{C}$ at a heating rate of $3{ }^{\circ} \mathrm{C} / \mathrm{min}$ and sintered for $1 \mathrm{~h}$. Finally, the sintered samples were machined to the required shape and size.

The thermal conductivities were measured using a high-temperature thermal conductivity tester (DRS-III). An insulation tile was machined for X-ray tomography. Then, the surface morphology was examined using field-emission scanning electron microscopy (SEM, Apollo300, CamScan Company, USA). For the FE-SEM test, the sample was crushed onto carbon tape and imaged at $20 \mathrm{kV}$ after surface gold sputtering.

\subsection{Data Acquisition via X-ray Tomography}

The experiment was performed, and in-line phase contrast X-ray images were acquired using beamline BL13W1 at the Shanghai Synchrotron Radiation Facility (SSRF). The schematic layout of in-line phase-contrast $X$-ray microscopy is shown in Figure 1. A collimated X-ray beam was monochromatized by a double $\mathrm{Si}(311)$ crystal system. The X-ray energy was adjusted to $35 \mathrm{KeV}$ by taking into account edge enhancement and transmission rate. When the X-ray beam traversed the sample, the exiting beam carried both absorption and phase shift information. After propagating for a sufficient distance $(100 \mathrm{~cm})$, the phase shifts were transformed into measurable intensity variations by Fresnel diffraction. The distance was determined according to the best image contrast. As shown in Figure 1, the absorption contrast at position I can be selected, while the image contrast is very low for materials with a similar absorption coefficient [45]. To enhance the image contrast, the detector was moved to position II in the experiment. The obtained images represent the hybrid of absorption and phase shift information. A CCD detector $(2048 \times 2048$ pixels and pixel size of $6.5 \times 6.5 \mu \mathrm{m}$ ) was used to transform the beam into an image. The specimen was fixed on a rotary stage that was strictly calibrated to parallel the CCD camera and rotated $180^{\circ}$ during data acquisition. The detector collected 360 projection images from $0^{\circ}$ to $180^{\circ}$ at a $0.5^{\circ}$ rotation interval, and the exposure time for each projection was $6 \mathrm{~ms}$, taking into consideration the image quality and data acquisition time. The projection number was determined by the sample size. To achieve satisfactory spatial resolution in tomography, the projection number $(N)$ is determined by $N \approx \pi \mathrm{D} /(2 \mathrm{P})$ to $\pi \mathrm{D} /(4 \mathrm{P})$, where $\mathrm{D}$ is the thickness of the sample and $\mathrm{P}$ is the detector pixel size [45,46]. Two flat images without samples in the beam path were collected every 90 projections and used to calibrate the background. Five dark images without $\mathrm{X}$-rays in the beam path were recorded to eliminate the CCD dark noise.

\subsection{Tomographic Reconstruction and 3D Volume Rendering}

The tomographic reconstruction, including background correction, rotating axis position correction, and filtered back projection (FBP) reconstruction, was carried out using CT software compiled by the BL13W1 station [47]. 


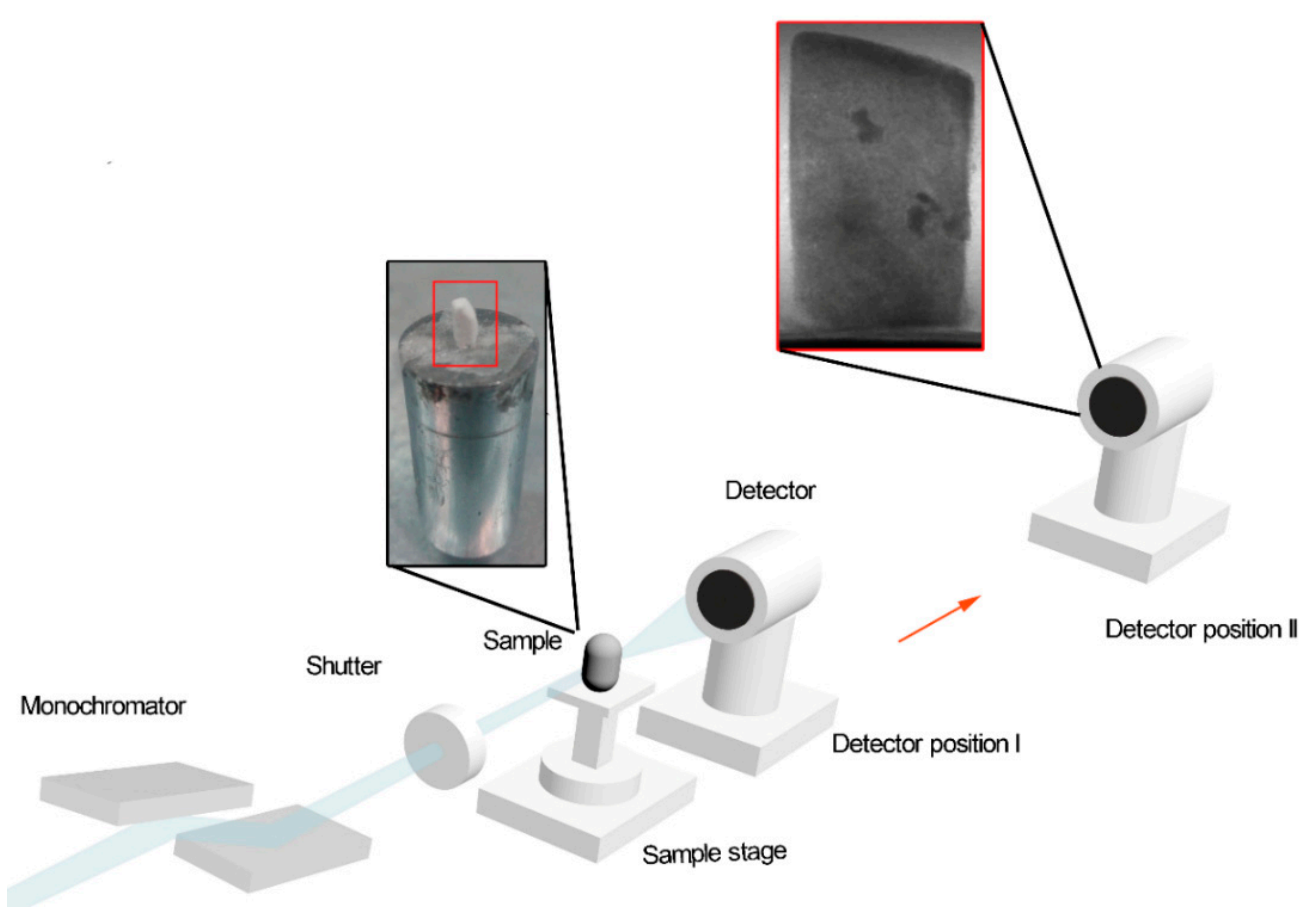

Figure 1. Schematic layout of in-line phase-contrast X-ray tomography.

The background correction was a procedure used for avoiding the artifacts induced by the illuminating beam, CCD detector, and other elements such as beryllium windows and filters in the beam path. Furthermore, the dark signal of the CCD detector in the absence of photons was also subtracted from the projection images. Thus, according to Beer's law, the corrected images can be expressed as

$$
\operatorname{prj}=-\log \left(\left(I-I_{D}\right) /\left(I_{0}-I_{D}\right)\right),
$$

where $I, I_{0}$, and $I_{D}$ are the recorded projection, flat-field, and darkfield image, respectively. Accordingly, the projection data for tomographic reconstruction were obtained.

In tomographic reconstruction, the projections should be along a common tilt axis. The tilt axis may have an arbitrary shift along the $x-, y-$, and $z$-axes in the experiment, where $y$ is the tilt axis and $z$ is the beam direction. The shift was corrected using the centerof-mass method. In this method, the center of mass of all the tomographic projections was calculated as

$$
R=\sum_{i} r_{i} \rho\left(r_{i}\right) / \sum_{j} \rho\left(r_{j}\right),
$$

where $R$ is the center of mass, and $\rho\left(r_{i}\right)$ and $\rho\left(r_{j}\right)$ are the mass densities of a projection image at positions $r_{i}$ and $r_{j}$. Then, a vertical axis through the center of mass was set as the new axis, and all the projections were aligned to it.

Then, the 3D structures were reconstructed using FBP algorithms in which a SheppLogan filter was used. The reconstruction took about $15 \mathrm{~s}$ with the FBP algorithm using an HP Z800 workstation (Dual Intel Xeon X5675 @ 3.07 GHz). Subsequently, the threedimensional images of the sample were visualized with Amira software.

\section{Results and Discussion}

In this study, we explored the application of synchrotron X-ray in-line phase-contrast tomography in the structural analysis of yttria-stabilized $\mathrm{ZrO}_{2}$ aerogels. The yttria-stabilized $\mathrm{ZrO}_{2}$ insulation tile was fabricated by mixing a slurry of zirconia fibers and silica binder, followed by vacuum molding and sintering (Figure 2a). The yttria-stabilized $\mathrm{ZrO}_{2}$ fibers in the insulation tile mainly bonded at the junctions of adjacent fibers, as shown by scanning electron microscopy (Figure 2b). This morphology coincides with previous results [17]. The 
interconnection of adjacent fibers is important to the thermal conductivity and mechanical properties of the material [1]. The binding of adjuncts and the porosity play important roles in determining the mechanical properties of porous ceramics. To achieve high mechanical properties, the fibers should be dispersed uniformly and bond tightly at the fiber junctions instead of simply stacking without interconnections. In terms of low thermal conductivity, the axial direction of the fibers should be perpendicular to heat flow. However, in Figure 2, the SEM images only exhibited the surface morphology, in which the fibers were arranged randomly in a slice. The detailed structural information inside the sample, including the porosity, aggregation state, and arrangement of the fibers was not very clear. When using optical microscopy or SEM, the samples would have to be sliced and observed layer by layer. This process is time-consuming, and there is a risk of destroying the sample.

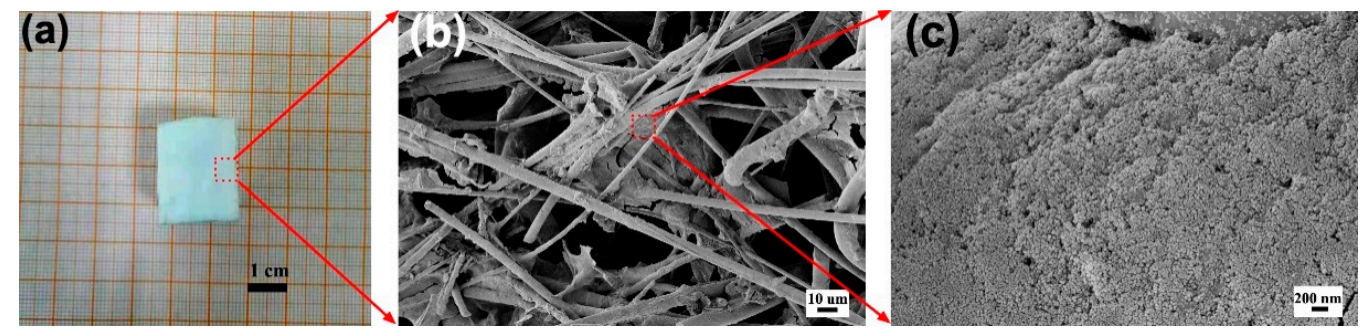

Figure 2. (a) Optical and (b,c) SEM images of the yttria-stabilized $\mathrm{ZrO}_{2}$ fiber insulation tile.

Compared with optical microscopy and scanning electron microscopy, X-ray microscopy can nondestructively realize three-dimensional structural analysis. Herein, for tomographic imaging, projection images from $0^{\circ}$ to $180^{\circ}$ at a $0.5^{\circ}$ rotation interval were acquired at an X-ray energy of $35 \mathrm{KeV}$. The whole sample was imaged nondestructively at this energy, and the transmission rate was $30-50 \%$. The resulting $X$-ray images were formed as a function of the transmission of the $\mathrm{X}$-rays through the material. In the projections, the internal ultrastructure could be clearly observed (Figure 3 ). The dark dots represent the aggregates of zirconia fibers and silica binder, which could not be observed by optical microscopy or electron microscopy without destroying the samples. The aggregations are considered defects which would deteriorate mechanical strength. According to the structure information provided by X-ray images, in the fabrication process, the fiber slurry should be further diluted in order to avoid such aggregations. Moreover, single fibers could also be observed at the boundary of the insulation tiles due to the effect of edge enhancement during in-line phase-contrast $\mathrm{X}$-ray imaging.

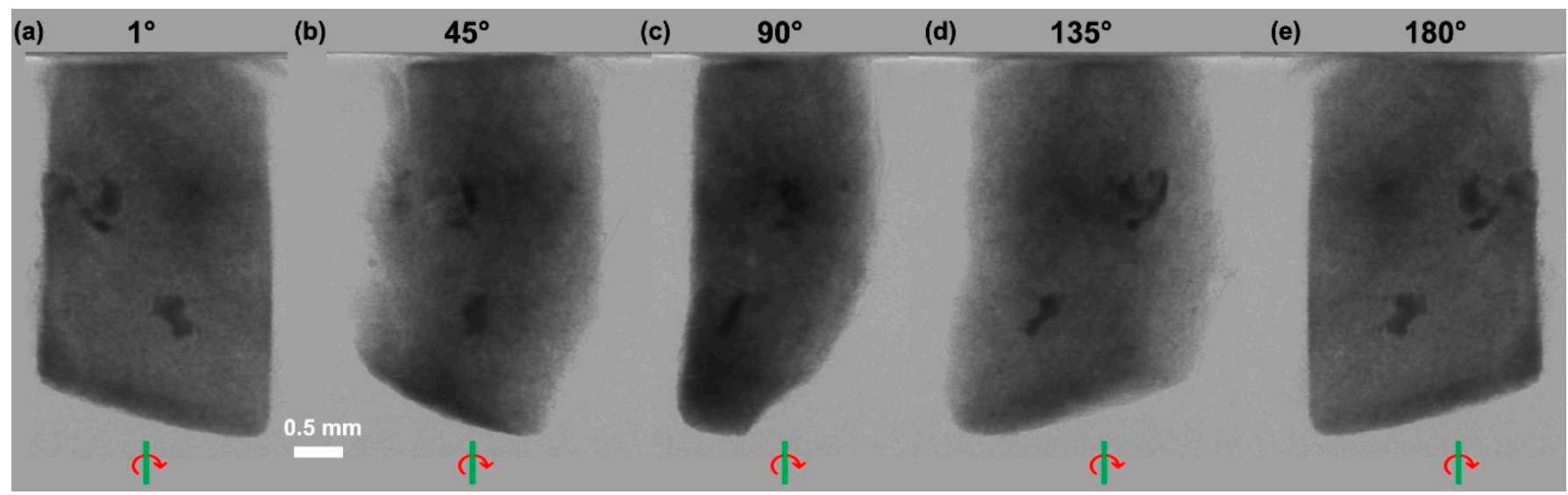

Figure 3. Tomographic projections at different tilt angles: (a) $1^{\circ},\left(\right.$ b) $45^{\circ}$, (c) $90^{\circ}$, (d) $135^{\circ}$, and (e) $180^{\circ}$.

X-ray tomography is an ideal approach for imaging intact specimens without destroying them owing to the long penetration depth of X-rays. Herein, the tomography of the yttria-stabilized $\mathrm{ZrO}_{2}$ fiber insulation tile was performed, and the $3 \mathrm{D}$ virtual microstructure 
was obtained nondestructively. The tomographic reconstructed virtual sample could be rotated along any axis. Figure 4 shows the 3D morphology of the yttria-stabilized $\mathrm{ZrO}_{2}$ fiber insulation tile at three orthometric viewpoints (the rotating axis in green). Figure $4 \mathrm{a}$ is front view, in which the width of the sample was measured. The sample width was about $6 \mathrm{~mm}$. By rotating the virtual sample $90^{\circ}$, the side view was obtained, according to which the thickness of the insulation tile was about $5 \mathrm{~mm}$. By rotating the virtual sample another $90^{\circ}$, the back view was obtained. Moreover, the height was also measured to be about $9 \mathrm{~mm}$. In addition to accurately measuring the sample size, the single fibers could be observed clearly. The fibers were distinguished by taking advantage of the edge enhance effect of in-line phase-contrast X-ray microscopy. Phase-contrast imaging is based on the phase shift of X-rays, and it significantly improves the resolution capability compared with absorption-based radiography. The method shows great potential in the structural analysis of a sample with similar chemical constituents.

(a)

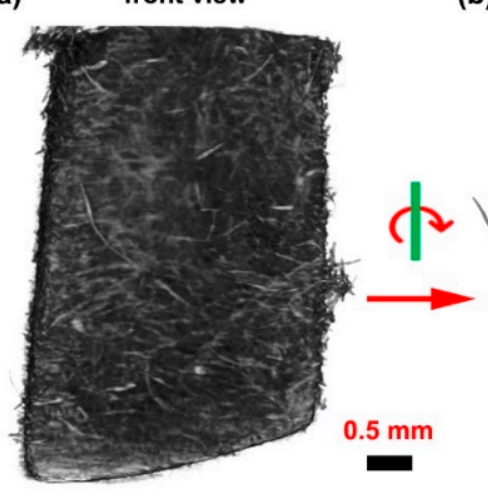

(b)

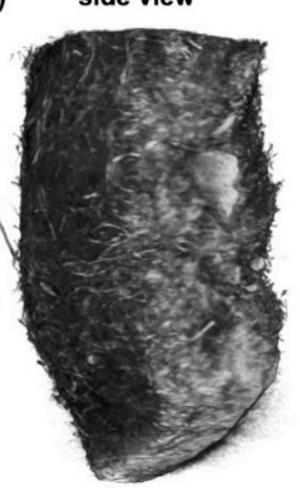

(c)

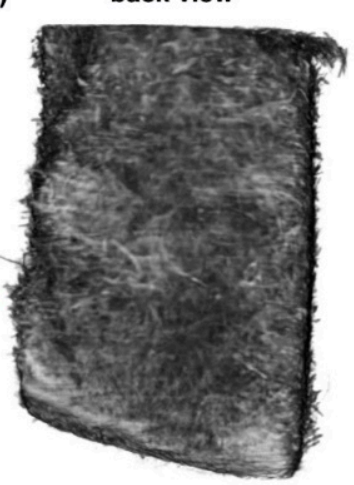

Figure 4. The 3D morphology of the yttria-stabilized $\mathrm{ZrO}_{2}$ fiber insulation tile at three orthometric viewpoints. The sample was rotated along the axis in green: (a) front view, (b) side view, and (c) back view.

The microstructure of the yttria-stabilized $\mathrm{ZrO}_{2}$ fiber insulation tile was reconstructed by X-ray tomography. In comparison with the histological methods that are often technically difficult and labor-intensive, X-ray tomography shows high efficiency and high precision in noninvasive structural analysis. Figure 5a shows the side view of the 3D microstructure, from which the morphology information can be observed. To investigate the interior structures, the sample was virtually analyzed slice by slice. Figure $5 b$ is a representative slice with $6.5 \mu \mathrm{m}$ thickness, whose position is shown in blue in Figure $5 \mathrm{a}$. Figure $5 c$ is another slice, showing the aggregates formed during sintering at high temperature. In the future, we will investigate the composition of the aggregates by combining X-ray spectroscopy and imaging or EDS after sample section.

Thus, according to 2D and 3D structural analysis, we can find that the yttria-stabilized $\mathrm{ZrO}_{2}$ fibers and silica binder formed aggregates during sintering. Morphologies such as the interconnection and dispersion of fibers are tightly related to the synthesis conditions, such as the type of binder used and the sintering temperature the concentration of the slurry [17]. Furthermore, the thermal conductivity and mechanical properties of a material are related to its microstructure. For instance, according to the side view shown in Figure $5 b$, some fibers were arranged across the tile. Generally, yttria-stabilized $\mathrm{ZrO}_{2}$ tiles are used perpendicular to heat flow, i.e., as in the front view shown in Figure 4a. When the fibers are arranged across the tile, as shown in Figure 5b, these fibers are susceptible to heat transfer; the heat flow would transmit rapidly along the axial direction of the fibers. In this study, the thermal conductivity of the fiber tiles was measured to be $\sim 0.1 \mathrm{~W} /(\mathrm{m} \cdot \mathrm{K})$ at $1273 \mathrm{~K}$. To improve the thermal conductivities and mechanical properties of materials, their microstructure should be further modified; for example, during the fabrication process, the fiber slurry could be further diluted in order to avoid such aggregations. 
(a)

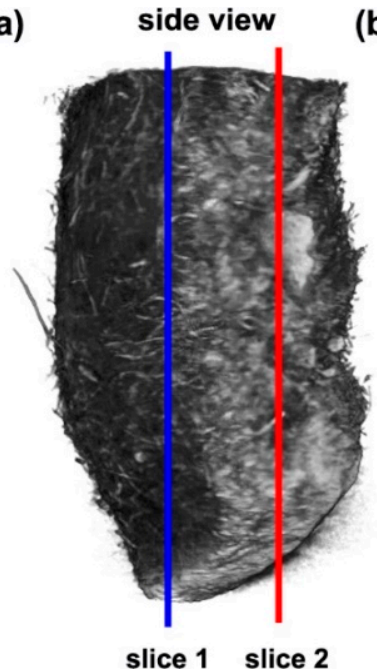

(b)

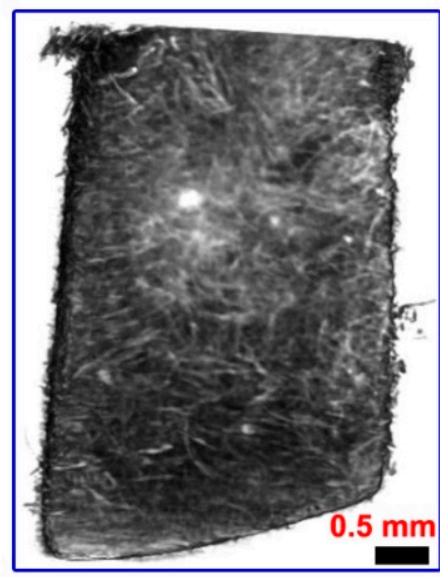

(c)

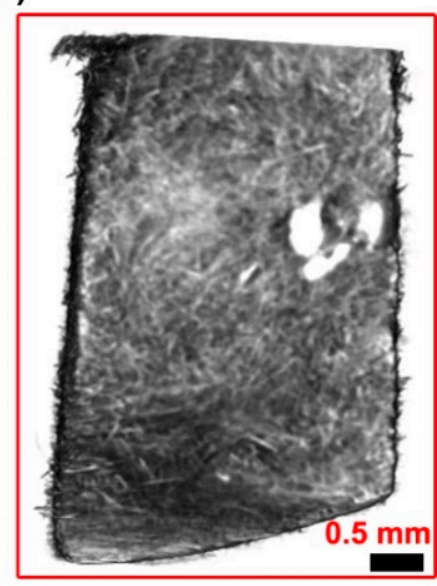

Figure 5. Two representative virtual slices with a thickness of $6.5 \mu \mathrm{m}$ showing the interior aggregates: (a) 3D morphology of the yttria-stabilized $\mathrm{ZrO}_{2}$ fiber insulation tile at a side view, (b) virtual slice 1 in blue, and (c) virtual slice 2 in red.

To explore the potential of X-ray tomography in the study of yttria-stabilized $\mathrm{ZrO}_{2}$ fiber insulation tiles, we investigated only one experimental condition. The study verified the feasibility and high efficiency of the methodology. In the future, various different conditions will be further studied using synchrotron X-ray in-line phase-contrast microtomography. We anticipate that the understanding of the relationship between aerogel microstructure and function will be further improved.

\section{Conclusions}

In conclusion, we demonstrated the structural analysis of an yttria-stabilized $\mathrm{ZrO}_{2}$ fiber insulation tile without destroying the sample, using synchrotron X-ray in-line phasecontrast microtomography. Single yttria-stabilized $\mathrm{ZrO}_{2}$ fibers were clearly distinguished, and interior aggregates were also nondestructively observed. This work implies the advantages and potential of synchrotron X-ray microtomography for the structural analysis of porous ceramic materials. Imaging technology will play more important roles in the further understanding of the relationship between aerogel microstructure and function.

Author Contributions: Conceptualization, S.Y., B.L., and Y.C.; methodology, S.Y.; software, M.Q.; validation, S.Y., B.L., and Y.C.; formal analysis, J.R. and J.L.; writing—original draft preparation, S.Y. All authors have read and agreed to the published version of the manuscript.

Funding: This research was funded by the National Natural Science Foundation of China (12004227 and 11947117), the Shandong Provincial Natural Science Foundation (ZR2020QA076 and ZR2020QE070), and the Postdoctoral Science Foundation of China (2019M660164).

Data Availability Statement: The data that support the findings of this study are available from the corresponding author upon reasonable request.

Acknowledgments: We thank the staff at the Shanghai Synchrotron Radiation Facility for assistance with data acquisition.

Conflicts of Interest: The authors declare no conflict of interest.

\section{References}

1. Shin, S.; Wang, Q.; Luo, J.; Chen, R. Advanced Materials for High-Temperature Thermal Transport. Adv. Funct. Mater. 2020, 30, 1904815. [CrossRef]

2. Xu, X.; Zhang, Q.; Hao, M.; Hu, Y.; Lin, Z.; Peng, L.; Wang, T.; Ren, X.; Wang, C.; Zhao, Z.; et al. Double-negative-index ceramic aerogels for thermal superinsulation. Science 2019, 363, 723-727. [CrossRef] 
3. Jones, S.M.; Sakamoto, J. Applications of Aerogels in Space Exploration: Aerogels Handbook; Springer: Berlin/Heidelberg, Germany, 2011; pp. 721-746.

4. Jones, S.M. Aerogel: Space exploration applications. J. Sol-Gel Sci. Technol. 2006, 40, 351-357. [CrossRef]

5. An, L.; Wang, J.; Petit, D.; Armstrong, J.N.; Hanson, K.; Hamilton, J.; Souza, M.; Zhao, D.; Li, C.; Liu, Y.; et al. An All-Ceramic, Anisotropic, and Flexible Aerogel Insulation Material. Nano Lett. 2020, 20, 3828-3835. [CrossRef]

6. Abu-Jdayil, B.; Mourad, A.-H.; Hittini, W.; Hassan, M.; Hameedi, S. Traditional, state-of-the-art and renewable thermal building insulation materials: An overview. Constr. Build. Mater. 2019, 214, 709-735. [CrossRef]

7. Li, Y.; Sun, Y.; Qiu, J.; Liu, T.; Yang, L.; She, H. Moisture absorption characteristics and thermal insulation performance of thermal insulation materials for cold region tunnels. Constr. Build. Mater. 2020, 237, 117765. [CrossRef]

8. Kumar, D.; Alam, M.; Zou, P.X.; Sanjayan, J.G.; Memon, R.A. Comparative analysis of building insulation material properties and performance. Renew. Sustain. Energy Rev. 2020, 131, 110038. [CrossRef]

9. Liu, B.; Gao, M.; Liu, X.; Zhao, X.; Zhang, J.; Yi, X. Thermally Stable Nanoporous $\mathrm{ZrO}_{2} / \mathrm{SiO}_{2}$ Hybrid Aerogels for Thermal Insulation. ACS Appl. Nano Mater. 2019, 2, 7299-7310. [CrossRef]

10. Thapliyal, P.C.; Singh, K. Aerogels as promising thermal insulating materials: An overview. J. Mater. vol. 2014, $2014,127049$. [CrossRef]

11. Wang, L.; Liu, B.; Xie, Y.; Ma, D.; Zhu, L.; Wang, X. Effect of high-pressure vapor pretreatment on the microstructure evolution and tensile strength of zirconia fibers. J. Am. Ceram. Soc. 2019, 102, 4450-4458. [CrossRef]

12. Liu, B.; Lin, X.; Zhu, L.; Wang, X.; Xu, D. Fabrication of calcium zirconate fibers by the sol-gel method. Ceram. Int. 2014, 40, 12525-12531. [CrossRef]

13. Liu, B.; Liu, X.; Zhao, X.; Fan, H.; Zhang, J.; Yi, X.; Gao, M.; Zhu, L.; Wang, X. High-strength, thermal-stable $\mathrm{ZrO}_{2}$ aerogel from polyacetylacetonatozirconium. Chem. Phys. Lett. 2019, 715, 109-114. [CrossRef]

14. Yu, Z.; Liu, B.; Zhou, H.; Feng, C.; Wang, X.; Yuan, K.; Gan, X.; Zhu, L.; Zhang, G.; Xu, D. Mesoporous ZrO2 fibers with enhanced surface area and the application as recyclable absorbent. Appl. Surf. Sci. 2017, 399, 288-297. [CrossRef]

15. Wang, L.; Liu, B.; Zhu, L.; Xie, Y.; Lv, Y.; Xu, C.; Jin, X.; Wang, X.; Zhang, G.; Xu, D. Polyaceticzirconium for zirconia continuous fibers: Polymeric evolution process and the relationship between polymeric structure and rheological behavior. Ceram. Int. 2017, 43, 14176-14182. [CrossRef]

16. Elsen, S.R.; Ramesh, T. Shrinkage characteristics studies on conventional sintered zirconia toughened alumina using computed tomography imaging technique. Int. J. Refract. Met. Hard Mater. 2016, 54, 383-394. [CrossRef]

17. Sun, J.; Hu, Z.J.; Li, J.N.; Zhang, H.B.; Sun, C.C. Thermal and mechanical properties of fibrous zirconia ceramics with ultra-high porosity. Ceram. Int. 2014, 40, 11787-11793. [CrossRef]

18. Nait-Ali, B.; Haberko, K.; Vesteghem, H.; Absi, J.; Smith, D.S. Thermal conductivity of highly porous zirconia. J. Eur. Ceram. Soc. 2006, 26, 3567-3574. [CrossRef]

19. Hondo, T.; Kato, Z.; Yasuda, K.; Wakai, F.; Tanaka, S. Coarse pore evolution in dry-pressed alumina ceramics during sintering. Adv. Powder Technol. 2016, 27, 1006-1012. [CrossRef]

20. Semeraro, F.; Ferguson, J.C.; Panerai, F.; King, R.J.; Mansour, N.N. Anisotropic analysis of fibrous and woven materials part 1: Estimation of local orientation. Comput. Mater. Sci. 2020, 178, 109631. [CrossRef]

21. Semeraro, F.; Ferguson, J.C.; Acin, M.; Panerai, F.; Mansour, N.N. Anisotropic analysis of fibrous and woven materials part 2 : Computation of effective conductivity. Comput. Mater. Sci. 2021, 186, 109956. [CrossRef]

22. Cottrino, S.; Jorand, Y.; Maire, E.; Adrien, J. Characterization by X-ray tomography of granulated alumina powder during in situ die compaction. Mater. Charact. 2013, 81, 111-123. [CrossRef]

23. Ahlhelm, M.; Werner, D.; Maier, J.; Abel, J.; Behnisch, T.; Moritz, T.; Michaelis, A.; Gude, M. Evaluation of the pore morphology formation of the Freeze Foaming process by in situ computed tomography. J. Eur. Ceram. Soc. 2018, 38, 3369-3378. [CrossRef]

24. Bernard, D.; Gendron, D.; Heintz, J.-M.; Bordère, S.; Etourneau, J. First direct 3D visualisation of microstructural evolutions during sintering through X-ray computed microtomography. Acta Mater. 2005, 53, 121-128. [CrossRef]

25. Wu, S.C.; Xiao, T.Q.; Withers, P.J. The imaging of failure in structural materials by synchrotron radiation X-ray microtomography. Eng. Fract. Mech. 2017, 182, 127-156. [CrossRef]

26. Saucedo-Mora, L.; Lowe, T.; Zhao, S.; Lee, P.D.; Mummery, P.M.; Marrow, T.J. In situ observation of mechanical damage within a SiC-SiC ceramic matrix composite. J. Nucl. Mater. 2016, 481, 13-23. [CrossRef]

27. Maire, E.; Colombo, P.; Adrien, J.; Babout, L.; Biasetto, L. Characterization of the morphology of cellular ceramics by 3D image processing of X-ray tomography. J. Eur. Ceram. Soc. 2007, 27, 1973-1981. [CrossRef]

28. Bale, H.; Blacklock, M.; Begley, M.R.; Marshall, D.B.; Cox, B.N.; Ritchie, R.O. Characterizing three-dimensional textile ceramic composites using synchrotron X-ray micro-computed-tomography. J. Am. Ceram. Soc. 2012, 95, 392-402. [CrossRef]

29. Fan, W.; Yang, P.; Yang, Z. Freeze-thaw impact on macropore structure of clay by 3D X-ray computed tomography. Eng. Geol. 2021, 280, 105921. [CrossRef]

30. Saâdaoui, M.; Khaldoun, F.; Adrien, J.; Reveron, H.; Chevalier, J. X-ray tomography of additive-manufactured zirconia: Processing defects-strength relations. J. Eur. Ceram. Soc. 2020, 40, 3200-3207. [CrossRef]

31. Vertyagina, Y.; Mostafavi, M.; Reinhard, C.; Atwood, R.; Marrow, T.J. In situ quantitative three-dimensional characterisation of sub-indentation cracking in polycrystalline alumina. J. Eur. Ceram. Soc. 2014, 34, 3127-3132. [CrossRef] 
32. Larson, N.M.; Zok, F.W. In-situ 3D visualization of composite microstructure during polymer-to-ceramic conversion. Acta Mater. 2018, 144, 579-589. [CrossRef]

33. Moralesrodriguez, A.; Reynaud, P.; Fantozzi, G.; Adrien, J.; Maire, E. Porosity analysis of long-fiber-reinforced ceramic matrix composites using X-ray tomography. Scr. Mater. 2009, 60, 388-390. [CrossRef]

34. Moritz, K.; Moritz, T. $\mathrm{ZrO}_{2}$ ceramics with aligned pore structure by EPD and their characterisation by X-ray computed tomography. J. Eur. Ceram. Soc. 2010, 30, 1203-1209. [CrossRef]

35. Maskery, I.; Aboulkhair, N.T.; Corfield, M.R.; Tuck, C.; Clare, A.T.; Leach, R.K.; Wildman, R.D.; Ashcroft, I.A.; Hague, R.J.M. Quantification and characterisation of porosity in selectively laser melted Al-Si10-Mg using X-ray computed tomography. Mater. Charact. 2016, 111, 193-204. [CrossRef]

36. Maire, E.; Withers, P.J. Quantitative X-ray tomography. Int. Mater. Rev. 2014, 59, 1-43. [CrossRef]

37. Gao, Y.; Wang, Y.; Yang, X.; Liu, M.; Xia, H.; Huai, P.; Zhou, X. Synchrotron X-ray tomographic characterization of CVI engineered 2D-woven and 3D-braided SiCf/SiC composites. Ceram. Int. 2016, 42, 17137-17147. [CrossRef]

38. Andersson, L.; Jones, A.C.; Knackstedt, M.A.; Bergström, L. Three-dimensional structure analysis by X-ray micro-computed tomography of macroporous alumina templated with expandable microspheres. J. Eur. Ceram. Soc. 2010, 30, 2547-2554. [CrossRef]

39. Stock, S.R. Recent advances in X-ray microtomography applied to materials. Int. Mater. Rev. 2013, 53, 129-181. [CrossRef]

40. Shanti, N.O.; Chan, V.W.L.; Stock, S.R.; de Carlo, F.; Thornton, K.; Faber, K.T. X-ray micro-computed tomography and tortuosity calculations of percolating pore networks. Acta Mater. 2014, 71, 126-135. [CrossRef]

41. Zhu, P.; Zhang, K.; Wang, Z.; Liu, Y.; Liu, X.; Wu, Z.; McDonald, S.A.; Marone, F.; Stampanoni, M. Low-dose, simple, and fast grating-based X-ray phase-contrast imaging. Proc. Natl. Acad. Sci. USA 2010, 107, 13576-13581. [CrossRef]

42. Davis, T.J.; Gao, D.; Gureyev, T.E.; Stevenson, A.W.; Wilkins, S.W. Phase-contrast imaging of weakly absorbing materials using hard X-rays. Nature 1995, 373, 595-598. [CrossRef]

43. Westneat, M.W.; Betz, O.; Blob, R.W.; Fezzaa, K.; Cooper, W.J.; Lee, W.K. Tracheal respiration in insects visualized with synchrotron X-ray imaging. Science 2003, 299, 558-560. [CrossRef]

44. del Rio, M.S.; Chubar, O.; Pan, A.; Xu, L.; Petruccelli, J.C.; Gupta, R.; Barbastathis, G. Advances in Computational Methods for X-Ray Optics III. Proc. SPIE 2014, 9209, 92090R.

45. Yao, S.; Fan, J.; Zong, Y.; He, Y.; Zhou, G.; Sun, Z.; Zhang, J.; Huang, Q.; Xiao, T.; Jiang, H. Equally sloped X-ray microtomography of living insects with low radiation dose and improved resolution capability. Appl. Phys. Lett. 2016, 108, 123702. [CrossRef]

46. Zhao, Y.; Brun, E.; Coan, P.; Huang, Z.; Sztrokay, A.; Diemoz, P.C.; Liebhardt, S.; Mittone, A.; Gasilov, S.; Miao, J.; et al. Highresolution, low-dose phase contrast X-ray tomography for 3D diagnosis of human breast cancers. Proc. Natl. Acad. Sci. USA 2012, 109, 18290-18294. [CrossRef] [PubMed]

47. Chen, R.C.; Dreossi, D.; Mancini, L.; Menk, R.; Rigon, L.; Xiao, T.Q.; Longo, R. PITRE: Software for phase-sensitive X-ray image processing and tomography reconstruction. J. Synchrotron Radiat. 2012, 19, 836-845. [CrossRef] [PubMed] 